\title{
Study and Evaluation of Antibiotic Usage in Surgical Cases
}

\author{
IJCRR \\ Section: Healthcare \\ Sci. Journal Impact \\ Factor: $6.1(2018)$ \\ ICV: 90.90 (2018) \\ (c) (3) (8) \\ Copyright@IJCRR
}

\section{Amol Jeur, Mayur Nagavekar, Yogesh P. Nikam, Mansing Adnaik}

Department of Surgery, Krishna Institute of Medical Sciences Deemed To Be University, Karad, India.

\section{ABSTRACT}

Introduction: A surgical incision may be all the provocation bacteria need for the battle to begin. Notwithstanding the advances made in pre-employable asepsis, clean procedures, and prophylactic anti-toxins, patients exposed to tasks normally need to confront the danger of complexities.

Aim: Study was aimed at the evaluation of antibiotic usages in surgical cases.

Methods: A serial study of 200 patients was done who have undergone operative procedure due to some surgical problem, under the Department of Surgery.

Results: Overall incidence of postoperative wound infection in this study is $31 \% .70 \%$ of wound infections occur above the age of 50 years. malnutrition $(41.30 \%)$ and obesity $(50 \%)$ have a higher SSI rate than that of averagely nourished patients $(28.16 \%)$. The number of patients encountered in this study suffering from diabetes was 15 .

Conclusions: Infection rate rises with increasing degree of operative contamination; Risk of wound infection in elective and clean surgeries is airborne or endogenous, while in other categories The age of the patient exerts a direct influence on the occurrence of postoperative wound infection, Sex of the patient is apparently and indirectly related to the risk of infection, The rate of postoperative wound infection increases with poor nutritional status, poor hygiene and low socioeconomic status. To reduce the infection rate, nutritional status and hygiene of the patient should be improved, at least in elective surgical procedures.

Key Words: Antibiotic, Preoperative, Postoperative, Infection, Prevalence

\section{INTRODUCTION}

Skin is peppered with landmines, irrelevant bacterial bombs fundamentally lying in accept that the correct second will detonate vivaciously. For whatever timeframe that we are solid, they are typically squashed; an individual who is cleared out, notwithstanding, may have an undermined safe framework unequipped for raising protection. A careful cut might be all the provoking microorganisms need for the fight to begin. Despite the advances made in pre-employable asepsis, clean techniques, and prophylactic adversary of tainting administrators, patients introduced to practices consistently need to oppose the risk of complications. Therefore in any case an immense piece of them escape from these and have an ordinary post-usable period, sickness now and then is one of the most truly awful complexities. The most exhaustively observed hugeness of careful site soiling (SSI), is that made by Horan and associates and got by the Center for Disease Control (CDC), US. This parts SSIs into 3 gettogethers shallow and noteworthy incisional SSIs, and organ space SSIs-subordinate upon the site and level of disease. The CDC definition states that only infections occurring within 30 days of surgery (or within a year in case of implants) should be classified as SSIs ${ }^{1}$.

The problem ranges from a small stitch abscess to massive tissue necrosis with its incumbent morbidity and mortality. The target patient has the discomfort of a prolonged and painful post-operative convalescence, prolonged postoperative hospital stay, additional expenditure, nursing care, and unnecessary wastage of time.

It is well known that bacterial contamination of the wound does not necessarily lead to sepsis, as the body defence mechanism can destroy the pathogen unless the contamination is

\section{Corresponding Author:}

Dr. Mayur Nagavekar, Department of Surgery Krishna Institute of Medical Sciences Deemed To Be University, Karad, India. Email: hodsurgery@kimsuniversity.in

ISSN: 2231-2196 (Print)

Received: 15.09 .2020
ISSN: $0975-5241$ (Online)

Revised: 02.10 .2020
Accepted: 08.10 .2020
Published: 27.10 .2020 
overwhelming. This has been proved in many cases of frank purulent peritonitis, where the surgical incision healed without any signs of inflammation or suppuration.

Aside from bacterial sullying of the injury, there are numerous variables inside the patient and his condition, both neighbourhood and general, which at last decide the ultimate result.

Surgeons and their associates are taking efforts to prevent wound infection. Despite these efforts infections still develop and although our understanding of asepsis has improved, many infections in clean wounds remain unexplained. Also, the scope of surgery has broadened so greatly that operations are sometimes performed when body resistance is known to be decreased. For example in emergency surgery, in certain other cases as in transplant surgery, such reduction of resistance is inevitable.

The hospital environmental organisms are more often reported to be resistant to most of the antibiotics in routine use. The management of such infection raises multifold problems and so its early identification is of prime importance.

The occurrence of post-usable injury contamination changes from emergency clinic to the medical clinic and fluctuates in various examinations which have been accounted for now and again. The current investigation was thus attempted to consider the issue of post-employable injury contamination concerning different factors straightforwardly or by implication identified with post-usable injury disease and its administration.

\section{METHODS}

The study was approved by the institutional ethics committee. A study of 200 patients was done who have undergone operative procedure due to some surgical problem, under the Department of Surgery.

\section{Study of Patients}

All the cases that have undergone any type of surgery for any surgical cause were selected randomly. There were no specific criteria for age, sex, etc.

\section{A. Preoperative Phase}

In the preoperative period, thorough clinical examination was done and diagnosis and preoperative assessment was recorded regarding any factors that could lead to postoperative wound infection such as age, sex, socio-economic status, educational status, occupation, preoperative stay in the hospital, the preoperative focus of infection (local, distant or systemic), built of the patient, nutritional status (average, malnourished or obese) assessed by visual impression, history of diabetes mellitus, tuberculosis, jaundice, malignancy, ischemic heart disease, etc. Personal history of addiction to tobacco, smoking, and mishri use was also recorded.

Biochemical investigations and bacteriological screening using swab cultures were done.

\section{B. Intraoperative Phase}

In this phase, indication for operation and nature of operation i.e. elective or emergency were noted. Other factors such as operation theatre used, duration of operation, wound drainage, suction used, number and type of incision, blood loss during surgery, a surgical technique such as excessive handling of tissue, closure under tension, hemostasis, the material used for closure etc. were noted.

\section{Postoperative Phase}

In postoperative period dressings were opened on $3^{\text {rd }}$ postoperative day for clean cases and $2^{\text {nd }}$ postoperative period for infected cases. Then they were kept open after cleaning daily with spirit except for soakage, in such situation it was opened immediately and the new dressing was applied. Daily examination of the wound was done for assessment of the formation of a hematoma. The occurrence of induration, suppuration, gaping was noted.

\section{Study of Environmental Factors}

In this part of the study, an attempt was made to find out the source of infection. Because of this, the patient himself, his doctors, nurses, ward attendants, wards, operation theatre, as well as the articles, which he came in contact with, were swabbed and sent for culture.

\section{A. From Patients}

Swabs from the incision site, before and after preparation of the skin with Savlon, betadine and spirit were taken.

\section{B. From Wards}

Various material present in the wards were subjected to bacteriology. This included floor, walls, cots, blankets, mattresses, bedsheets, ward instruments, dressing trolleys, antiseptic solutions etc. were studied.

\section{From Operation Theatre}

Samples from the floor, tabletops, instrument trolleys, antiseptic solutions, dressing material, gowns, gloves etc. were obtained.

Statistical analysis- Descriptive statistical analysis was done with the help of SPSS 20 version. 
RESULTS

Table 1: Age and Sex Incidence

\begin{tabular}{|c|c|c|c|c|c|c|c|}
\hline \multirow{2}{*}{$\begin{array}{l}\text { Sr. } \\
\text { No. }\end{array}$} & \multirow{2}{*}{$\begin{array}{l}\text { Age in } \\
\text { years }\end{array}$} & \multicolumn{3}{|c|}{ Male } & \multicolumn{3}{|c|}{ Female } \\
\hline & & Total & Incidence & $\%$ & Total & $\begin{array}{l}\text { Inci- } \\
\text { dence }\end{array}$ & $\%$ \\
\hline 1. & $0-9$ & 9 & 3 & $33 \cdot 33$ & 3 & o & o \\
\hline 2. & $10-19$ & 11 & 3 & 27.27 & 10 & 2 & 20 \\
\hline 3. & $20-29$ & 22 & 3 & 13.63 & 10 & 3 & 30 \\
\hline 4. & 30-39 & 19 & 1 & 5.26 & 6 & 2 & 33.33 \\
\hline 5. & $40-49$ & 10 & 5 & 50 & 25 & 6 & 24 \\
\hline 6. & $50-59$ & 23 & 10 & 43.47 & 6 & 1 & 16.66 \\
\hline 7. & $6 o-69$ & 20 & 11 & 55 & 6 & 2 & 33.33 \\
\hline 8. & $\begin{array}{c}70-79 \\
\text { onwards }\end{array}$ & 13 & 6 & 46.15 & 7 & 4 & 57.14 \\
\hline & Total & 127 & 42 & 33.07 & 73 & 20 & $27 \cdot 39$ \\
\hline
\end{tabular}

Table 1 reveals that the majority of $46.15 \%$ males were in the age group of $70-79$ and above followed by $43.47 \%$ were from were in the age group of 50 to 59 years. While in females majority were $57.14 \%$ at the age group of were $70-79$ followed by 33.33\%in 60-69 and 30-39 years of age group. This is the incidence of infection in various age groups in both the sexes. The above table no 1 showed the incidence of infection in various age groups in both the sexes.

\section{Table 2: Nutritional Status}

\begin{tabular}{llccc} 
Sr. No. & Nutritional Status & Total & Infected & $\%$ \\
1. & Malnourished & 46 & 19 & 41.30 \\
2. & Well or Averagely & 142 & 40 & 28.16 \\
& nourished & & & \\
3. & Obese & 12 & 3 & 25 \\
& Total & 200 & 62 & 31 \\
\hline
\end{tabular}

This table no 2 shows the significance of nutrition in postoperative wound infection. Majority $41.30 \%$ were malnourished followed by $28.16 \%$ were from averagely nourished.

\section{Haemoglobin}

The small increase in the incidence of postoperative wound infection in patients with higher haemoglobin is actually due to dehydration and hemoconcentration masking the existing anaemia.

Preoperative Wound Type-Incidence of postoperative wound infection rises as the degree of contamination of preoperative wound increases.
Table 3: Preoperative Focus of Infection

\begin{tabular}{llccc} 
Sr. No. & Focus & Total & Infected & $\%$ \\
1. & Nil & 42 & 2 & 4.76 \\
2. & Local & 133 & 48 & 36.09 \\
3. & Distant & 20 & 9 & 45 \\
4. & Systemic & 5 & 3 & 60 \\
& Total & 200 & 62 & 31 \\
\hline
\end{tabular}

This table no 3 shows $36.09 \%$ had the preoperative focus of infection locally followed by $60 \%$ systemic focus of infection increased incidence of postoperative wound infection if there was a preoperative focus of infection.

Table 4: Duration of Surgery

\begin{tabular}{llccc} 
Sr. No. & Duration in hours & Total & Infected & $\%$ \\
1. & Less than 1 & 85 & 34 & 40 \\
2. & 1 to 2 & 94 & 19 & 20.21 \\
3. & More than 2 to 3 & 21 & 9 & 42.85 \\
& Total & 200 & 62 & 31 \\
\hline
\end{tabular}

Table no 4 reveals that the duration surgery .mostly surgery time more than $2-3$ hours were $42.85 \%$ followed by 1 to 2 hours for $20.21 \%$. The incidence of postoperative wound infection rises. There is a higher incidence in the first category because of minor abscesses, which had been drained in a short period but still got infected.

This is the incidence of infection according to the grades of infection, which has been already mentioned above.

\section{DISCUSSION}

\section{Incidence}

The overall incidence of postoperative wound infection in this study is $31 \%$.

Frequency of postoperative injury contamination fluctuates significantly in different examinations and various emergency clinics. In created nations, it was accounted for from as low as $0.83 \%$ to as high as $28 \%{ }^{3}$. The infection rates in US National Nosocomial Infection Surveillance (NNIS) system hospitals were reported to be: clean $2.1 \%$, clean-contaminated $3.3 \%$, contaminated $6.4 \%$ and dirty $7.1 \%{ }^{4}$. In another study, it was reported that SSIs account for $14 \%$ to $16 \%$ of hospital-acquired infections ${ }^{5}$.

\section{Age and Sex Incidence}

It can be seen that there is an increased incidence of postoperative wound infection in old age. This is probably due to decreased body resistance to infection, increased chances of 
atherosclerosis with less blood supply and oxygenation to the wound.

It has been observed that $70 \%$ of wound infections occur above the age of 50 years $^{6}$. It is concluded that the age of the patient plays a significant and direct role in determining the risk of SSI.

\section{Nutritional Status}

It has been observed that nutrition plays an important role in wound healing and resistance to infection. Increased incidence of infection in obesity has also been noted in several studies ${ }^{7}$. Accordingly, to prevent postoperative wound infection, serum proteins, electrolytes, fluid volume and haemoglobin levels should be corrected. They also have shown the relationship between low levels of plasma transferrin and wound infection along with low plasma prealbumin ${ }^{8}$.

In the present study, we too have results that indicate malnutrition (41.30\%) and obesity (50\%) have a higher SSI rate than that of averagely nourished patients $(28.16 \%)$.

\section{Hemoglobin}

The observation explains the importance of oxygenation in wound healing. Several studies also have proved that anaemia increases the incidence of $\mathrm{SSI}^{7}$.

\section{Preoperative Focus of Infection}

It has been shown that distant trauma increases the susceptibility of wound infection by decreasing the blood supply to the wound ${ }^{9}$. Also, the rate of SSIs is increased by the concurrent presence of remote and asymptomatic infections. They are easily overlooked and can triple the clean wound infection rate.

\section{Associated Diseases}

The number of patients encountered in this study suffering from diabetes was 15, that with malignancy was 7 and those with tuberculosis was 4 . Out of these patients, 12 diabetics, 3 tuberculous and 5 malignant patients got infected. So the results revealed that these factors increase the incidence of postoperative wound infection.

\section{Shock}

Of these 200 cases, 20 patients were in shock at the time of operation. 16 patients of these developed postoperative wound infection.

It has been proved that local blood supply is essential for localhost resistance. Shock induced in experimental animals to the point of impaired skin perfusion showed that the minimum dose of bacteria necessary to initiate infection reduced by 10,000 folds ${ }^{10}$. This explains the high rate of infection in patients having shock.

\section{Preoperative Hospitalization}

A definite relationship was found between preoperative hospitalization and the occurrence of infection.

It can be seen that the rate of infection is proportional to the duration of preoperative stay in the hospitalization ${ }^{7}$. A drawn-out preoperative remain with an introduction to medical clinic condition and its pervasive demonstrative methods, treatments and microflora has been appeared to expand the pace of $\mathrm{SSI}^{11}$.

\section{Other Host Factors}

Great progress has been made to find out various host defence mechanisms. Role of immunity in prevention of infection and various factors like abnormality of neutrophil function, opsonin defect, abnormal immunoglobulin, etc. has been studied ${ }^{12}$. These complicated laboratory procedures are not routinely clinically applicable.

\section{INTRAOPERATIVE PHASE}

\section{Operative Technique}

In this study of 200 cases, there was some variation in the surgical technique depending upon seniority and experience of the operating surgeon. However, by and large, the technique followed in each unit was identical to the pattern set by the senior surgeon of that unit. The strict aseptic technique right from the scrubbing of the wound till its dressing was followed in the operation theatre.

\section{Nature of Operation}

High incidence of infection in emergency cases was because-

i. Such cases was relatively unprepared.

ii. They were not clean.

iii. They were usually contaminated.

iv. Patients were in poor general condition.

Overcrowding by junior doctors and staff nurses, the poor general condition of the patient and contaminated wound are responsible for higher infection rate in emergency cases

In this study, most of the emergency cases were exploratory laparotomies and debridements.

\section{Duration of Surgery}

As the duration of surgery increases, the incidence of SSI increases. There is a direct relationship between the length of operating time and rate of infection ${ }^{11}$.

\section{Wound Type}

It has been shown that the SSI rate is least in clean wounds and increases with the degree of contamination. Infection rates in US National Nosocomial Disease Surveillance 
(NNIS) framework clinics were accounted for to be-perfect $2.1 \%$, clean-tainted $3.3 \%$, sullied $6.4 \%$, and filthy $7.1 \%{ }^{4}$.

\section{Wound Drainage}

In our study, we mainly used vacuum drains and corrugated rubber drains. A drain invariably produces some necrosis of tissue with which it comes in contact and decreases the power of resistance of that tissue. But given for necrotic tissue and infection, a drain becomes almost indispensable ${ }^{13}$.

\section{Irrigation}

Irrigation was invariably done after the end of operation before the closure of the wound. Irrigation is helpful only when gross contamination or soiling during surgery occurs. This can be explained on the basis that peritoneal irrigation with normal saline removes the debris, foreign material, exudates and reduces the dose of organisms which can be suitably handled by the host immune mechanism and thus reducing the chances of SSI.

On the other hand, unnecessary irrigation can make a localized infection generalized. Thus, the decision should be taken wisely. In our study, most of the irrigated wounds were grossly contaminated and so have a higher incidence of SSI.

\section{Suction}

Use of suction in clean cases is not required. In our study, it was only used in clean-contaminated, contaminated and dirty wounds, which shows $28.23 \%$ of infection rate. It has been shown that contaminated material still spills with suction to other non-infected sites in the operative field and spreads infection.

\section{Operative Procedures:}

The rate of SSI is higher in minor operations because it included the majority of the contaminated and dirty cases, e.g. abscesses.

The difference in the incidence of infection in various body systems is probably due to various proportions of the following factors inherent to the part of the system or operation-

\section{POSTOPERATIVE PHASE}

\section{Dressings}

Dressings following surgery play a major role in the prevention of wound contamination during the early postoperative period. In this study, we have used plaster-sealing adhesives over sterile gauze. Though there is evidence that a perfectly approximated wound seldom gets infected postoperatively, the dressing does play a role ${ }^{14}$.

\section{Analysis of Antibiogram}

The observation shows that Netilmicin is the most potent antibiotic. Out of the 62 cases infected, 30 were sensitive to Netilmycin, 25 were sensitive to Cefotaxime, 22 were sensitive to Cephalexin, 16 were sensitive to Bactrim and so on. None of them was resistant to all antibiotics.

\section{Bacteriology of Postoperative Wound Infection}

The observations show that Staphylococcus aureus is the commonest organism isolated from the postoperative wound infection followed by E.coli, Klebsiella etc.

\section{Operation Theatre}

In this part of our study, we took random samples from several places in the theatre during the span of this study. However, it has been found that very few numbers of positive swab cultures were obtained. The swabs were sent at two months interval and after surgery of an infected case from the operation theatre floor, walls, tables, instruments, instrument trolleys etc.

\section{Operating Team}

A potential source of wound infection other than the air of the operation theatre is the operating team itself. They not only contribute bacteria to pollute the operation theatre air but also contaminate the wounds by unnoticed punctured gloves and incomplete masking.

Medical Research Council (1968) pointed out that wearing a single mask for a prolonged operative session might increase the risk of contamination of wound from the outer surface. Several workers have stressed the need for changing mask and thorough scrubbing of hands for every new operation ${ }^{15}$.

\section{Surgical Wards}

In the wards, we have studied the immediate environment of the patient. It is well known that pseudomonas and klebsiella survive for a long time in damp surroundings such as found by us around the sinks ${ }^{16}$. We may point out here that the blankets in our hospital are not washed as frequently as other linen. This leads to cross-infection if a blanket used for an infected patient is reused for a clean patient without washing it. So far all the instruments, dressing material, catheters, instrument trays, Savlon, etc. were found sterile on repeated culture.

\section{Ward Personnel}

It appears that there is a risk of cross-infection from one to another during dressing. This mode of exogenous infection is known since a long time e.g. 'Typhoid Mary' who was responsible for typhoid fever in and around New York. However, there is a good deal of controversy regarding the possibility of closed surgical wounds getting contaminated or infected in the wards. 
Management of Postoperative Wound Infection Above observation, the table shows the management of postoperative wound infection in our hospital. In 138 patients, healing occurred with primary intention. In 40 cases, minor stitch abscess or superficial wound was gapping, which healed by the daily dressing. In 22 patients, we did secondary suturing for deep wound gapping and burst abdomen.

Appropriate Polyantimicrobial drug therapy was given in severe postoperative wound infections.

\section{CONCLUSIONS}

Infection rate rises with increasing degree of operative contamination; Risk of wound infection in elective and clean surgeries is airborne or endogenous, while in other categories. The rate of postoperative wound infection increases with poor nutritional status, poor hygiene and low socioeconomic status. To reduce the infection rate, nutritional status and hygiene of the patient should be improved, at least in elective surgical procedures.

\section{ACKNOWLEDGEMENT}

Authors acknowledge the immense help received from the scholars whose articles are cited and included in references to this manuscript. The authors are also grateful to authors/ editors/publishers of all those articles, journals and books from where the literature for this article has been reviewed and discussed

Conflict of interest: Nothing to report.

Source of funding: KIMSDU Karad

\section{REFERENCES}

1. Horan TC, Gaynes RP, Martone WJ, Jarvis WR, Emori TG. CDC definitions of nosocomial surgical site infections, 1992: a modification of CDC definitions of surgical wound infections. Infection Control \& Hospital Epidemiology. 1992 Oct;13(10):606-8.

2. Davis, J.M., Wolff, B., Cunningham, T.F., Drusin, L. and Dineen, P., 1982. Delayed wound infection: An 11-year survey. Archives of Surgery, 117(2), pp.113-117.
3. Doig CM, Wilkinson AW. Wound infection in a children's hospital. British Journal of Surgery. 1976 Aug;63(8):647-50.

4. Culver DH, Horan TC, Gaynes RP, Martone WJ, Jarvis WR, Emori TG, Banerjee SN, Edwards JR, Tolson JS, Henderson TS, Hughes JM. Surgical wound infection rates by wound class, operative procedure, and patient risk index. The American journal of medicine. 1991 Sep 16;91(3): S152-7.

5. Kirkland KB, Briggs JP, Trivette SL, Wilkinson WE, Sexton DJ. The impact of surgical-site infections in the 1990s: attributable mortality, excess length of hospitalization, and extra costs. Infection control and hospital epidemiology. 1999 Nov 1;20(11):725-30..

6. Shinde, R. V., Shinde, A. R., Pawar, S. K., Mohite, S. T., Patil, S. R., Karande, G. S., \& Shinde, M. B. Seroprevalence of hepatitis E virus (HEV) amongst the acute viral hepatitis patients attending a tertiary care hospital. International Journal of Advanced Science and Technology, 2020. 29(4), 1229-1234.

7. Shinde, R. V., Shinde, A. R., Mohite, S. T., Patil, S. R., Pawar, S. K., Karande, G. S., \& Shinde, M. B. Seroprevalence of hepatitis a virus (HAV) among the acute viral hepatitis patients attending a tertiary care hospital. International Journal of Advanced Science and Technology, 2020,29(3): 501-505.

8. Gottrup F. Wound closure techniques. Journal of Wound Care. 1999 Sep;8(8):397-400.

9. Conolly, W.B., Hunt, T.K., Sonne, M. and Dunphy, J.E., 1969. Influence of distant trauma on local wound infection. Surgery, gynaecology and obstetrics, 128(4):713-718.

10. Miles AA, Niven JS. The enhancement of infection during shock produced by bacterial toxins and other agents. British journal of experimental pathology. $1950 \mathrm{Feb} ; 31(1): 73$.

11. Lilani SP, Jangale N, Chowdhary A, Daver GB. Surgical site infection in clean and clean-contaminated cases. Indian journal of medical microbiology. 2005 Oct 1;23(4):249.

12. Hohn DC. Leukocyte phagocytic function and dysfunction. Surgery, gynaecology and obstetrics. 1977 Jan;144(1):99-104.

13. Williams RE, Jevons MP, Shooter RA, Hunter CJ, Girling JA, Griffiths JD, Taylor GW. Nasal staphylococci and sepsis in hospital patients. British Medical Journal. 1959 Oct 10;2(5153):658.

14. Howe CW, Mozden PJ. Postoperative infections: Current concepts. Surgical Clinics of North America. 1963 Jun 1;43(3):85982.

15. Davidson AI, Smith G, Smylie HG. A bacteriological study of the immediate environment of a surgical wound. British Journal of Surgery. 1971 May;58(5):326-33.

16. Shinde, M. B., Zagade, T. B., Potdar, N. J., \& Pawar, S. Occurrence and predictors of peripheral intravenous catheter induced complications at tertiary care hospital. International Journal of Advanced Science and Technology, 2020,29(2): 2928-2934. 